\title{
Influence of ethnicity on cultural use of pangolins in Ghana and its implications on their conservation
}

\author{
Maxwell Kwame Boakye ${ }^{1^{*}}$
}

\begin{abstract}
Ethnicity has been documented to have an influence on the selection of medicinal resources and food. Pangolins are scaly mammals widely used for traditional medicine and consumed as bushmeat among local communities across Africa, yet no study has documented the influence of ethnicity on the cultural use of pangolins. The aim of this study was to determine the influence of ethnicity on the cultural use of pangolins in Ghana. Data on the use of pangolin for traditional medicine were gathered from 300 traditional medicinal practitioners from the major ethnic groups in Ghana through semi-structured individual interviews. Also, 150 chopbar operators were interviewed to determine the level of pangolin bushmeat preferences and consumption amongst the different ethnicity in Ghana. Peculiarities in knowledge, ethnic endogamy, inter-ethnic relations, and segregation in the settlement among the various ethnic groups affected the selection and use report of pangolin body parts and the assemblage of ethnic groups. Ethnicity did not have any influence on the consumption of pangolin bushmeat, however, scarceness of pangolin bushmeat was the main factor that affected the frequency of consumption. The findings of this study highlight the importance of cultural uses of pangolins by different ethnicities and how this information can be used to contribute to the design of a more effective and targeted conservation management strategy for these rare mammals.
\end{abstract}

Keywords: Pangolin; Ghana; Traditional Medicine; Bushmeat; Conservation

${ }^{1}$ Independent Researcher, P. O. Box KS 11041, Adum, Kumasi, Ghana

*Corresponding author. $\square$ E-mail address: MKB (boakyem@gmail.com

\section{INTRODUCTION}

The use of wild animals in African for traditional medicine and bushmeat purposes represent a practice deeply rooted in the continent's cultural values (Adeola 1992). One mammal that is highly valued for traditional medicine and bushmeat purposes by the majority of central and West African countries is the pangolin ( $\mathrm{Fa}$ et al. 2006, Soewu \& Sodeinde 2015, Boakye et al. 2014, 2015, 2016a). In Ghana, pangolins are highly sought after for their purported medicinal values and for consumption as 
bushmeat (Boakye et al. 2015, 2016a). The white-bellied pangolin (Phataginus tricuspis), the black-bellied pangolin (Phataginus tetradactyla), and the giant ground pangolin (Smutsia gigantea), that occur in Ghana have been listed as 'Vulnerable' on the IUCN Red List (IUCN, 2017) and recently up listed from CITES Appendix II to Appendix I in January 2017. In addition, the Wildlife Conservation Act of 1971 (LI 685) classifies pangolins under Schedule 1, prohibiting any person from hunting or being in possession of pangolins. However, the unique cultural values attached to pangolins for traditional medicine and bushmeat purposes may still account for their demand and supply in Ghana, despite their conservation status.

Considering that different ethnic groups have cultural underpinnings that account for their cultural values, cultural values attached to pangolins may differ based on ethnicity. Ethnicity influences the selection of medicinal resources and food around the world (Nestle et al. 1998, Thomas et al. 2009, Junsongduang et al. 2014, Agada \& Igbokwe 2016, Chithra et al. 2016). Traditional medicinal resources selection, patronage and use as well as on food are influenced by ethnicity in Ghana (Nti 2008, Kusi-Bempah 2011, Gadegbeku et al. 2013, Soelberg et al. 2015). Previous studies in Ghana on the traditional medicinal use and bushmeat consumption of pangolins did not place emphasis on ethnicity, despite its influence on cultural use. Indeed, with the exception of a study that focused on the Yoruba ethnic group in Nigeria (Soewu \& Ayodele 2009, Soewu \& Adekanola 2011), no other study on pangolin cultural use in Africa has focused specifically on ethnicity. However, an understanding of the differences and similarities in cultural values associated with pangolins by ethnic groups can assist in assessing the level of threats, identifying and targeting conservation management priorities based on the values attached to pangolins by an ethnic group. There is an assertion that native communities tend to possess deeper knowledge about medicinal resources in their environment (Codjia \& Yorou 2014, Medeiros et al. 2016, Vandebroek 2016). The objective of this study was to determine the traditional medicinal and bushmeat cultural values attached to pangolins by the major ethnic groups in Ghana. The findings from the study could be useful in the development of a conservation management policy for these endangered mammals.

\section{MATERIAL AND METHODS}

\section{Study area}

The study area fell within the High Forest Zone of Ghana, which is situated in the Upper Guinea Forest and classified as a global biodiversity hotspot having a high diversity of flora and fauna (Kouame et al. 2012). Farming is the primary economic activity within these regions, with cocoa and maize accounting for $95 \%$ of the total harvest value of crops (Ghana Statistical Service 2008). Some of the major threats contributing to a reduction in biodiversity in this ecological zone include conversion of land cover for cocoa farming, bushmeat hunting, increased human settlement as a result of the rapid population growth within the country and mining activities (Ministry of Environment and Science-Ghana 2002). The area is also home to different sociolinguistic communities, coexisting with varied social, religious and ethnic backgrounds that have been identified as effective microcosm for studying medicinal cultures in West Africa (James 2014). Also, all the ethnic groups had access to pangolins as previously 
reported (Boakye et al. 2016a) as this study falls within the natural distribution of two species of arboreal pangolins ( $P$. tricuspis and $P$. tetradactyla) (Figure1). In geographically close and environmentally homogeneous environments, one would expect the even distribution of traditional medicinal knowledge (Menendez-Baceta et al. 2015, Kujawska et al. 2017).

A purposeful sampling approach, which involves the selection of respondents more knowledgeable on the study subject, and a snowball sampling approach, which is the use of a targeted population to recommend

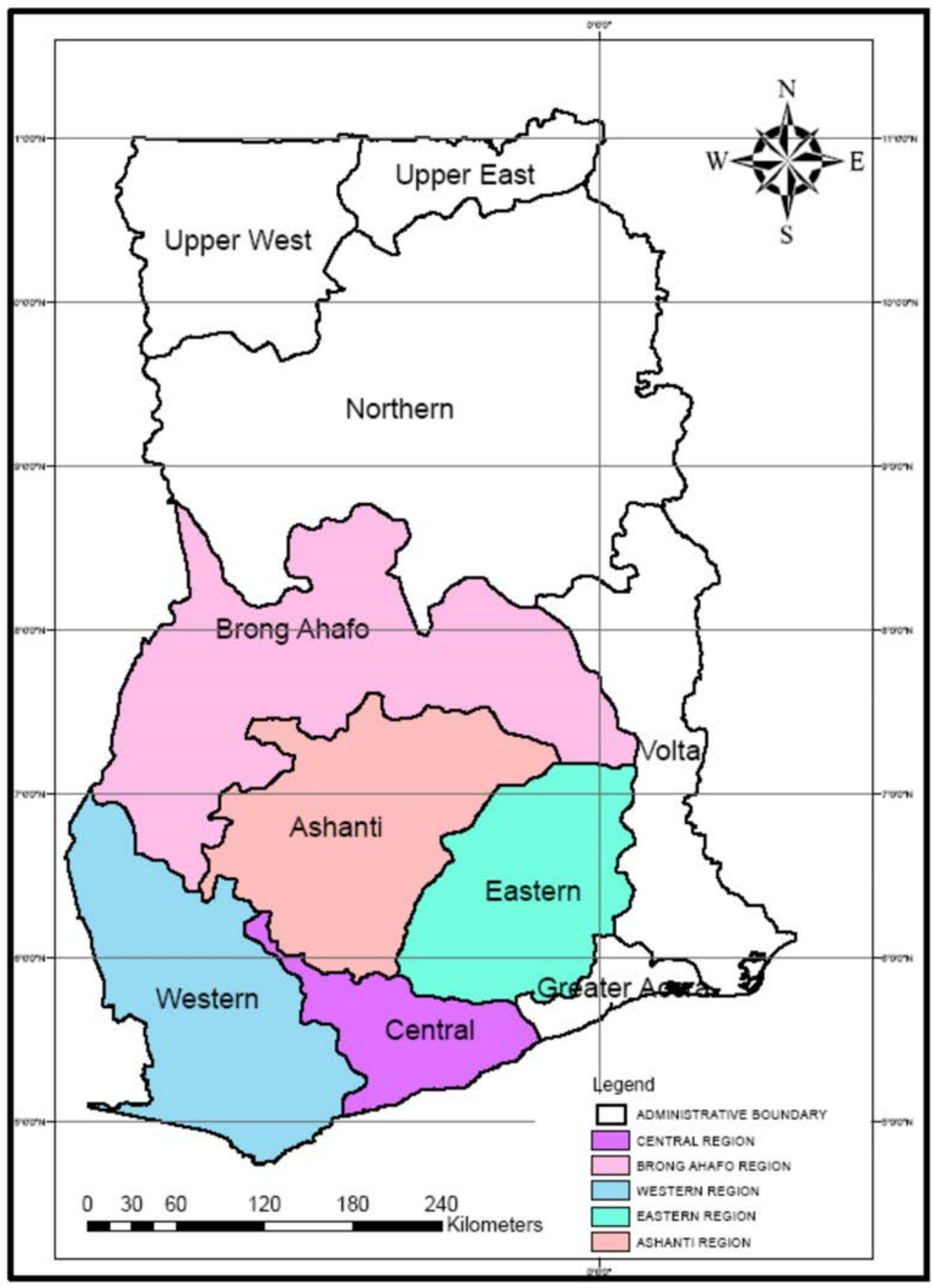

Figure 1. Map of Ghana indicating study regions 
other members of that population (Babbie 2004) were used. The sampling approaches ensured that participants who could provide information pertinent to this study were selected as representatives of this study. Traditional medical practitioners and chopbar operators were targeted as they were deemed to have wealth of knowledge about the cultural use of pangolins in Ghana (Boakye et al. 2015, 2016a, b). Also, participants were required to be affiliated to one of the recognised ethnic groups in Ghana. Ethnicity here refers to a group of people who possess common cultural attributes and based on this classification, the Akan, Ewe, Ga Adangbe, Guan, Gurma, Grusi, and Mole-Dagbani constitutes the major ethnic groups in Ghana (Asante \& Gyimah-Boadi 2004, Ghana Statistical Service 2012). Data were collected from respondents between May and December 2017.

\section{Data collection Traditional medicinal use}

A total of 300 traditional medicinal practitioners, comprising 10 from each of the recognised ethnic groups in Ghana, with the exception of the Ga-Adangbe were selected from the administrative regions of Ashanti, Brong-Ahafo, Central, Eastern and Western. The Ga-Adangbe ethnic group were excluded from the study because pilot survey revealed that they did not have knowledge about pangolin medicinal use. The loss of cultural knowledge has been identified as the greatest threat to the GaAdangbe traditional medicinal knowledge (Soelberg et al. 2015). Data collection procedure and questions followed the pattern used in previous studies on pangolin traditional medicinal use (Boakye et al. 2014, 2015). Also, respondents knowledge of pangolins intrinsic values (totems, spiritual and religious) and aesthetic or non-use values were asked.

\section{Bushmeat use}

Chopbars make the majority of pangolin bushmeat sales to the public in Ghana (Boakye et al. 2016a). A total of 150 chopbar operators were chosen for this study with 30 operators selected from five administrative regions of Ashanti, Brong-Ahafo, Central, Eastern, and Western. Within each administrative region, 15 chopbar operators were selected from town operators and 15 from roadside (rural) operators to determine any differences in the consumption of pangolin bushmeat in relation to geographic location as location influences the choice of chopbars by clients (Mensah et al. 2016). The snowball sampling approach inevitably produced a non-random cross section of chopbar operators. To ensure that the referrals made led to chopbar operators that are known to trade in bushmeat, commercial drivers were engaged in the identification and confirmation of the referrals in each district of each administrative region. Chopbars serves as a rest stop for commercial drivers and these establishments provide them with access and knowledge of what is available for consumption in these eating establishments.

The questionnaire on pangolin bushmeat consumption was designed to include (1) the frequency of pangolin bushmeat consumption (the frequency was noted as: weekly when pangolin bushmeat had been part of a meal in the previous week; monthly when it had been part of a meal the previous month; and occasionally when it had been part of a meal in more than a month),(2) the three most commonly prepared bushmeat species, (3) any known influence for choice 
of pangolin bushmeat which were limited to scarcity and cultural as these two factors are known to influence choice of bushmeat in Ghana (Cowlishaw et al. 2005), (4) taboos against the consumptions of pangolin bushmeat amongst the clientele. All data obtained from the chopbar operators through the semi-structured interviews were corroborated through direct observation and triangulation with other respondents.

\section{Data Analysis Traditional medicinal use Use Value Index (UV)}

The use value index was used to establish the cultural importance of whole or body parts of pangolin to the traditional medicinal practitioners from the various ethnic groups. The use value index developed by Albuquerque et al. (2006) was modified by using the number of informants within each ethnic group to determine cultural importance within the group rather than the total number of informants. The UV approach is based on a quantitative method to demonstrate the importance of species parts given by a local population (Alves et al. 2012). This procedure has been used to determine the cultural importance of pangolin in Sierra Leone in a previous study (Boakye et al. 2014). The UV of each pangolin body part mentioned was determined using the formula:

$$
U V=\frac{\sum U p}{n}
$$

where: Up=the number of uses mentioned by each informant for a given pangolin body part affiliated with an ethnic group, $n=$ the total number of informants within the ethnic grouping.
The Bray-Curtis distance measure was used to assess the similarity between ethnicity and pangolin body parts selection based on presence and absence of a pangolin body part in traditional medicinal pharmacopeia of the ethnic group using the PC-ORD software program (McCune \& Mefford 2006). Following this, a two-way cluster analyses was performed and this allowed for the assignment of simultaneously ethnic groups and body parts used by performing two separate cluster analyses. This allowed for the identification of the class (body part) and abundance per class that were responsible for grouping certain ethnic groups closer together. This analyses was also performed with the use of the PC-ORD software, with a Sørenson distance measure and group-average linking method without relativisation. The results were presented as a cluster analysis.

\section{Bushsmeat use}

All statistical analyses were completed using the IBM SPSS Statistical data analysis software package (Version 19). Descriptive statistics were performed, using a multiple response test to determine the frequency of selection of the various options of animal protein. A Kruskal-Wallis one-way analyses of variance was used to test if there were variations in the frequency of preparation of pangolin bushmeat by chopbar operators. A t-test was performed to note any difference in choice based on scarcity and cultural influence. All statistical interpretation was made at a $95 \%$ confidence limit. 


\section{RESULTS}

\section{Traditional medicinal use}

A total of 15 pangolin body parts were identified to be used for traditional medicinal purposes for the treatment of human ailments by the traditional medicinal practitioners from the major ethnic groups in Ghana (Table 1). However, all the members of the Akan ethnic group admitted that their knowledge about pangolin body part use was from oral folklore and not based on current practice. The most shared pangolin body parts among the ethnic groups were the scales, head, bone and meat. The scales were applied mostly for spiritual protection and treatment of rheumatism, with the exception of the Akan that used it to treat child bone development. The scale was found to have the highest use value for all the ethnic groups followed by the head (Table 1). All 300 traditional medicinal practitioners did not have knowledge of any taboo associated with use of pangolins for traditional medicinal purposes or as food.

There was strong variation in pangolin body parts used between the various ethnic groups as presented in the cluster analysis (Figure 2). The Akan ethnic group was the most dissimilar from all the other ethnic groups as they only make use of pangolin scales and no other body part. However, the Gurma and Ewe ethnic groups clustered together as did the Mole-Dagbani and Grusi as they were found to make use of similar body parts for traditional medicinal purposes.

A two-way cluster analyses (Figure 3 ) clearly indicated why the Mole-Dagbani and Grusi cluster were close to each other as both ethnic groups make use of similar pangolin body parts (head, bones, tail, whole animal and claws). The Gurma and Guan ethnic groups clustered together, as both make frequent use of the pangolin head, meat and heart. The Ewe people were somewhat separated from other ethnic groups, as they uniquely make use of pangolin tongue, intestines and liver.

\section{Bushmeat use}

The frequency of preparation of pangolin bushmeat by chopbar operators revealed a significant difference between weekly, monthly and occasional (KW=99.319, $\mathrm{P}<0.05$ ) (Figure 4). Dunn's multiple comparisons test revealed a significantly higher occasional preparation, followed by monthly and then weekly. Analysis of

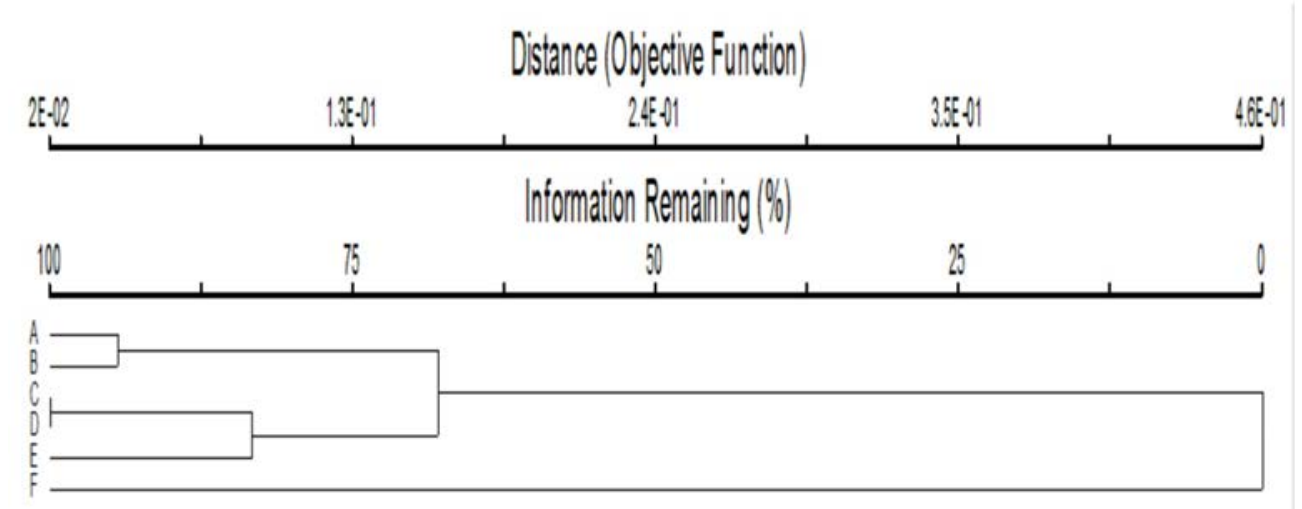

Figure 2. Hierarchical cluster analysis and the similarity of the use of various body parts for traditional medicine between ethnic groups - A: Mole- Dagbani, B: Grusi, C: Gurma, D: Ewe, E: Guan, and F: Akan 


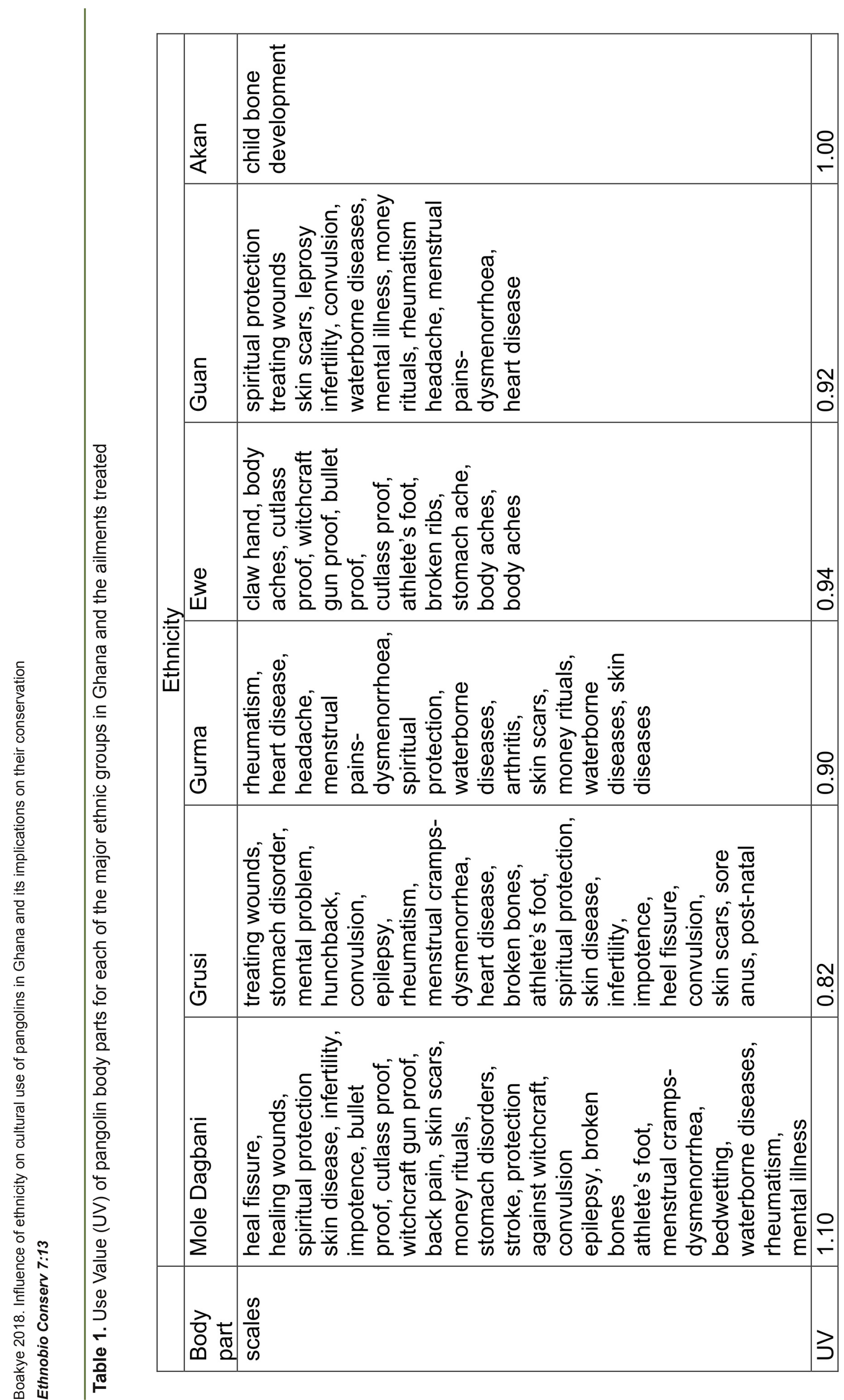




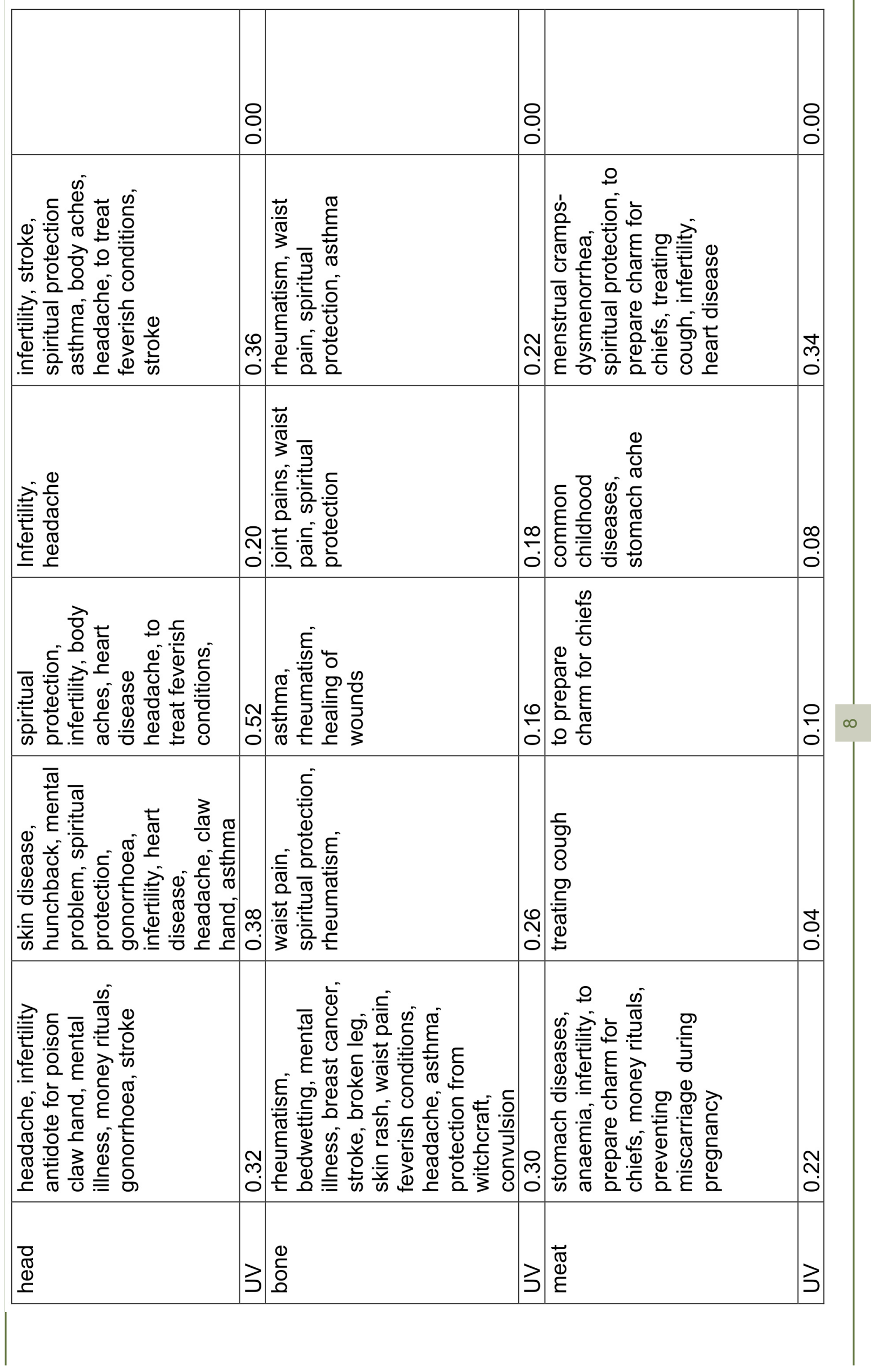




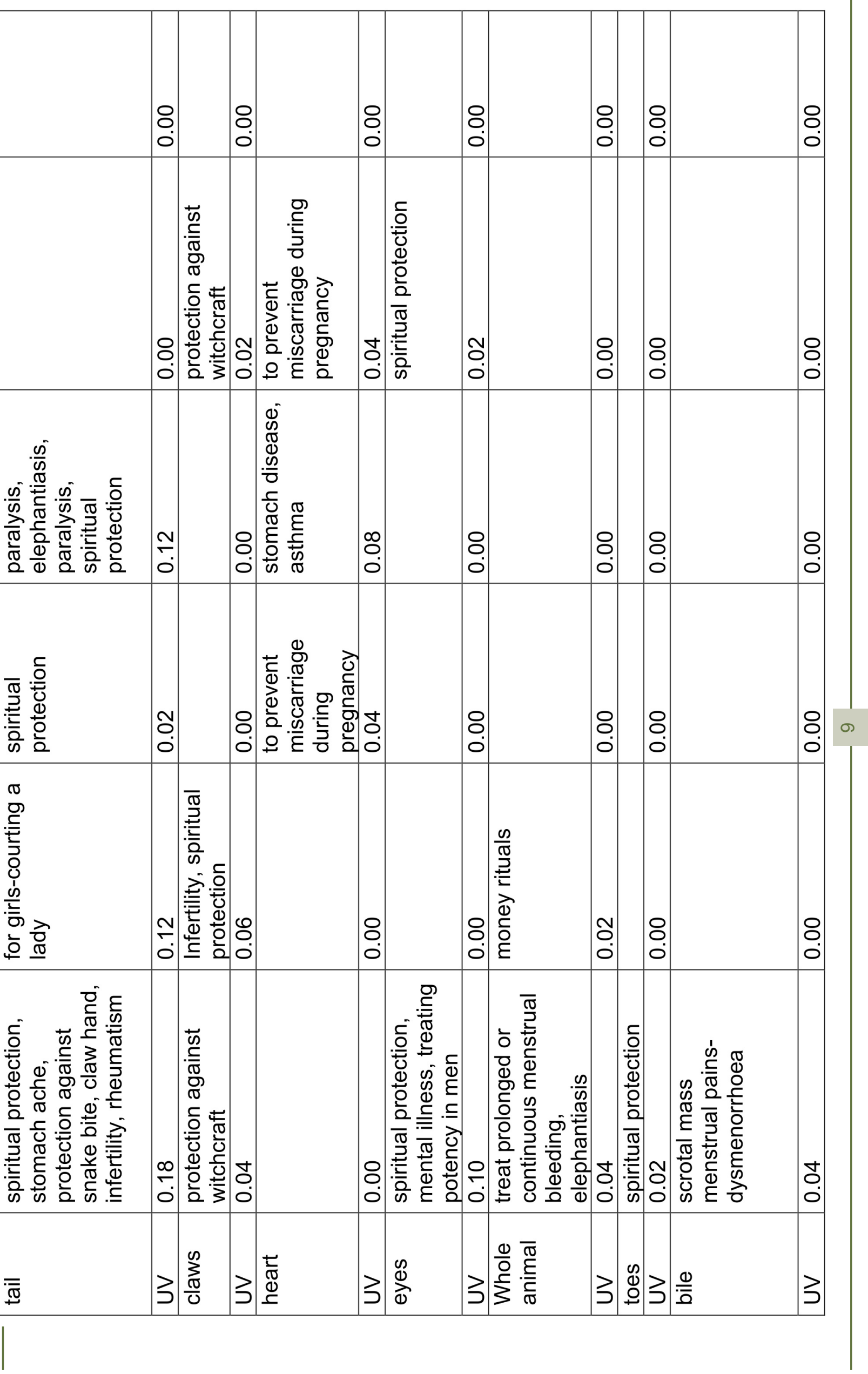




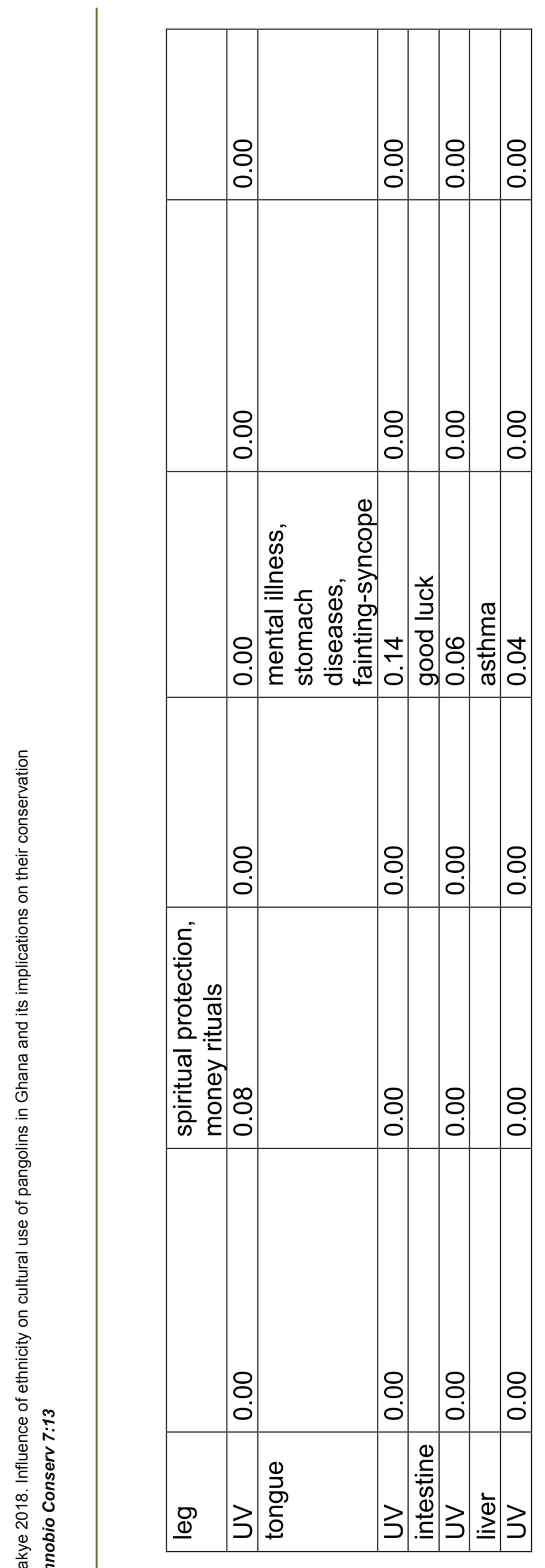




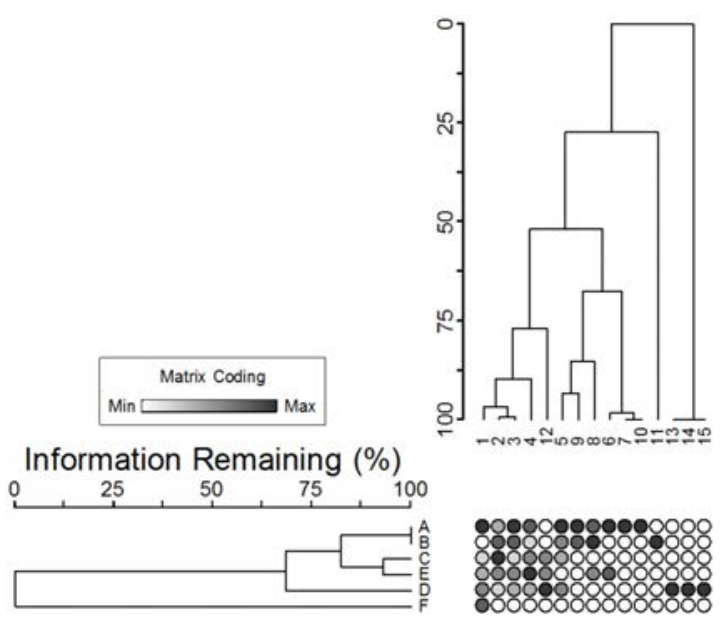

Figure 3. Two-way cluster analyses of ethnic assemblages and their preference for pangolin body parts (use report) (A: Mole-Dagbani, $B$ : Grusi, C: Gurma, D: Ewe, E: Guan, F: Akan) (1:scale, 2: head, 3: bones, 4: meat, 5: tail, 6: eyes, 7: toes, 8: claws, 9: whole pangolin, 10: bile, 11: leg, 12: heart, 13: tongue, 14: intestine, 15: liver)

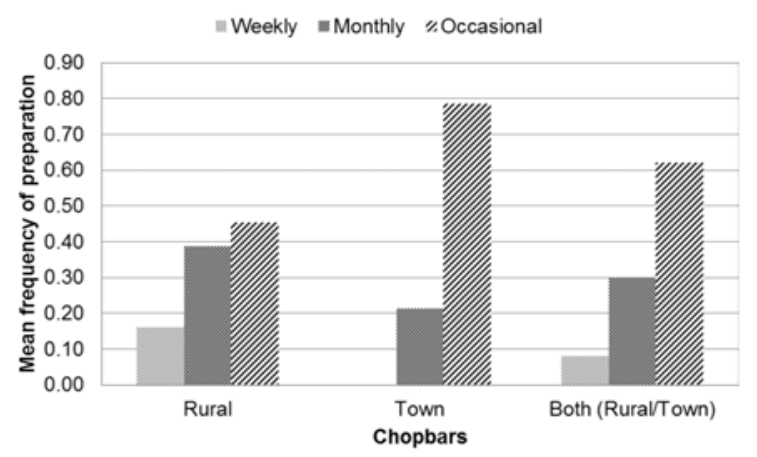

Figure 4. Frequency of preparation of pangolin bushmeat by chopbar operators

frequency of preparation of pangolin bushmeat revealed a significant difference between weekly, monthly and occasional preparation by town chopbar operators $(\mathrm{KW}=111.22, \mathrm{P}<0.05)$ as well as roadside chopbar operators $(\mathrm{KW}=15.889, \quad \mathrm{P}<0.05)$. Dunn's multiple comparisons test revealed a significantly higher occasional preparation over monthly and weekly for town chopbar operators. A significantly higher occasional preparation was recorded over weekly but no significance recorded between occasional and monthly preparation for roadside chopbar operators. The three most frequently cooked bushmeat species were the grasscutter (Thryonomys swinderianus) $100 \% \quad(n=150)$, giant pouched rat (Cricetomys gambianus) 69\% $(n=103)$ and the royal antelope (Neotragus pygmaeus) $53 \%(n=79)$. Overall, consumers of town chopbars choose pangolin bushmeat due to its scarceness as pangolins are not usually available and consumers are eager to taste (t-test=5.216; $p=0.05$ ). However, roadside chopbar operators reported a higher cultural value towards the consumption of pangolin bushmeat (t-test $=4.301 ; p=0.05$ ). All 150 chopbar operators interviewed did not have knowledge of any taboo associated with cooking pangolin bushmeat and could also not recall if a customer refused pangolin bushmeat due to a taboo.

\section{DISCUSSION}

\section{Traditional medicinal use}

The pangolin body parts used and the suite of ailments for which it was prescribed for the treatment of human ailments has been recorded in previous studies (Soewu \& Ayodele 2009, Soewu \& Adekanola 2011, Boakye et al. 2014, 2015). The high cultural importance of pangolin scales and the set of human ailments in this study were similar to those found in previous studies (Soewu \& Ayodele 2009, Soewu \& Adekanola 2011, Boakye et al. 2014, 2015). Scales are commonly used for spiritual protection and the treatment of rheumatism and this can be attributed to its strong establishment in traditional medicinal pharmacopeia. The use of the tongue, intestine, and liver by the Ewe ethnicity was not recorded in a previous 
study in Ghana (Boakye et al. 2015) but has been recorded in Sierra Leone and Benin (Akpona et al. 2008, Boakye et al. 2014). The lack of traditional medicinal knowledge about pangolins by the Ga-Adangbe ethnic group could also be attributed to their loss of traditional medicinal knowledge.

The differences observed in the selection and use reports for pangolin body parts can be attributed to peculiarities of ethnomedicinal knowledge of each ethnic group. The distribution of ethnomedicinal knowledge follows a pattern whereby few remedies are known to almost everyone while most knowledge is idiosyncratic (Thomas et al. 2009, Vandebroek 2010, Junsongduang et al. 2014, Boakye et al. 2014, 2015). According to Asante \& GyimahBoadi (2004), the easy geographic and high social mobility amongst various ethnic groups in Ghana has not weakened ethnic bond. The ethnic bond is maintained through ethnic endogamy which is the cooperation among same group members (AcedoCarmona \& Gomila 2015a) and may have facilitated idiosyncrasy in knowledge. The selection and use of different body parts for the treatment of different ailments can be considered as a demonstration of culturally specific knowledge that has developed within each ethnic group.

The variation in selection and use reports of pangolin body parts could also be attributed to inter-ethnic relations. For instance, the inter-ethnic tension between the Gurma and particularly the MoleDagbani (Awedoba 2006) may have accounted for their dissimilarity in the selection and use of pangolin body parts On the contrary, there is shared historical and cultural association between the MoleDagbani and Grusi leading to the assimilation and blending of some cultural aspects (Awedoba 2006; Acedo-Carmona \&
Gomila 2015b, Opoku et al. 2017) that may have accounted for the similarities in the selection and use of pangolin body parts between the two ethnic groups. The influence of relational factors among ethnic groups as a factor in the transfer of ethnomedicinal knowledge in this study, as a predictor of species knowledge and use has been reported by previous investigators (Chithra et al. 2017, Soares et al. 2017).

The relative lack of medicinal knowledge about pangolin between the Akans and the other ethnic groups may be attributed to the stratification in the settlement locals and migrants that may have affected of knowledge sharing. Most migrants in southern Ghana, particularly those from northern Ghana, settle in Zongo (literally, stranger's quarter) in major towns. Zongos have their own unique cultural practices that are completely different from any community within which they are situated in southern Ghana (Alhassan 2015). The unique culture pertaining to Zongos where respondents that were interviewed and had originated from the north of Ghana resided and their segregation from the Akan ethnic group, may have prevented knowledge sharing on pangolin medicinal use.

\section{Bushmeat use}

Ethnicity was not a factor in the consumption of pangolin bushmeat. This observation was consistent with a similar study undertaken by Kamins et al. (2015). The lack of ethnic influence on the consumption of pangolin bushmeat can be attributed to food acculturation amongst the various ethnic groups in Ghana. The staple food for most people in the study area is fufu which is consumed with a variety of soups usually prepared with bushmeat. In food acculturated situations, the settler 
communities adopt food identities of the host communities and cultural foods become prominent only on ceremonial occasions (Goody \& Goody 1995). According to OffeiAnsah (2013), there is a high level of acceptance of food that is readily available and culturally acceptable to people living in an area in Ghana by migrant communities.

As previously noted by McNamara et al. (2016) in a study on wildlife trade and supply, the results from this study also indicated scarcity as one of the main reasons influencing consumption levels of bushmeat in Ghana. A large proportion of the respondents believed that pangolin bushmeat has become more difficult to obtain with a higher perception of scarcity accounting for the occasional consumption of pangolin bushmeat. These findings suggest that bushmeat preferences are not fixed but adapted according to circumstance. The possibility exists that if pangolin is to become more readily available than other wildlife species, then consumers may opt for the other species that are scarcer over pangolin. Bushmeat species consumption levels are therefore driven not by consumer choice of wildlife species but rather by shortfalls in supply. The influence of psychosocial factors of perceptions, belief, attitudes, and values in shaping food behaviours and choices (Nestle et al. 1998) may have influenced the selection of pangolin bushmeat. Pangolin bushmeat is commonly referred to as "chiefs' meat" giving it symbolism of importance in its consumption.

Whilst cultural food taboos do not necessarily reduce the hunting level of taboo species, such taboos do reduce the trade value of these species as well as the total number that are consumed (van Vliet \& Mbazza 2011, Morsello et al. 2015). Taboos on certain foods are widespread in Ghana
(Gadegbeku et al. 2013) but the lack of taboo associated with pangolins may lead increased trade in these rare mammals and to contribute towards increased hunting pressure.

\section{Conservation Implications of Pangolin Use}

The importance of documenting data on cultural values of animal species can reveal the true value of the species (both utilitarian and intrinsic), which can lead to a more informed decision in the planning around sustainable offtake levels and conservation management plans (Koura et al. 2011). The cultural values associated with pangolins in Ghana by the different ethnicity reveal that pangolin use for bushmeat consumption and traditional medicinal purposes poses a threat that is of a different magnitude. Pangolin use for bushmeat purposes is less of a threat to their conservation as it can be easily withdrawn or replaced with an alternative species. The grasscutter (Thryonomys swinderianus) is the most preferred and frequently consumed bushmeat mammal species in Ghana (Conservation International-Ghana 2002). Even when cultural values influence consumption of pangolin bushmeat, it only does so when it is available and does not lead to their targeted hunting. According to Fa et al. (2015), in situations where bushmeat makes the most significant and direct contribution to food security as the main source of protein, curbing consumption as a dietary supplement becomes a challenge. Whilst the consumption of bushmeat is an integral part of the cultural heritage of many Ghanaians, the consumption of pangolin bushmeat is not the main source of protein but trade in these mammals for bushmeat purposes needs to be carefully monitored in order to determine 
any sharp changes to the trend in their trade.

In Ghana, there are several diseases and perceived causes that cannot be explained easily through the nosology of western medicine or where western medicine is not the first choice of treatment. Based on a previous study in Ghana (Boakye et al. 2015) and reflecting on the results from this study, it can be inferred that the most important reason people still value pangolin body parts in traditional medicine is their role in treating folk illnesses. The use of pangolin body parts for the treatment of spiritual protection, protection against witchcraft, money rituals, etc poses the greatest threat to the harvest of wild pangolins since these are ailments with complex etiology which local communities consider untreatable by western medicine due to it supernatural nature. Health, disease, success or misfortunes are most often attributed to spiritual and supernatural causes with a persistent belief in witchcraft and other spiritual forces as the cause of diseases and misfortunes among Ghanaians (Onyinah 2002, White 2015). The majority of people seek out the therapeutic services of traditional healers due to their cultural views, irrespective of educational and social status or religious sect of individuals (Konadu 2008). Considering the high level of acceptance of traditional medicine as well as the belief system definition of illnesses, it would difficult to curb the traditional medicinal use of pangolins particularly when used to treat folk diseases. Also, data with regards the turnover rates of certain species within traditional medicinal markets, which is essential information when calculating impact upon a population of a species from harvest, is difficult to obtain. The trade in pangolins for traditional medicinal purposes is open to individuals who patronise traditional medicine making it extremely difficult to obtain reliable information on amounts and turnover rates of pangolins traded. Even when it is open to the general public, the random sizes of pieces makes it difficult to reliably assess the level of trade unlike the bushmeat trade where it is often possible to have the whole animal or reasonable size of body parts for estimation of numbers traded.

The history of mistrust and animosity between the wildlife traders and conservation authorities needs to be addressed if cultural aspects of pangolin use are to be curtailed. Current pangolin conservation initiatives are rooted in the biological discipline that focuses on measuring the impact of harvesting and criminalization of human use as part of current conservation policies. There is a need to focus pangolin conservation campaigns on their scarceness as revealed in this study and in a previous study (Boakye et al. 2016) and how cultural values are impacting on their diminution. According to Morsello et al. (2015), insofar as people respond to the perception that current hunting regimes are unsustainable with a decreased in general wildlife numbers, local people may respond positively to outreach campaigns aimed at raising the awareness of species conservation. Also, communities are enthusiastic about changing attitudes and behaviour if they are made aware of the conservation and legal status of a species (Ntiamoa-Baidu 1995, Pailler 2005). People with interests in the cultural use of pangolins need to be sensitized about the need for their protection, particularly on the impact of their loss not only affecting biodiversity but the local communities cultural values as well. 


\section{CONCLUSION}

This study revealed that ethnicity has an influence on the selection and use of pangolin body parts for traditional medicinal purposes. Pangolin body parts were more important to traditional healers who have their roots from northern and the eastern parts of Ghana. Conservation management awareness campaigns related to pangolins should therefore be targeted at people from these ethnic backgrounds, if the focus is to curtail the tide of traditional medicinal use of these mammals. Although pangolin use for dietary purposes was not seen as a major threat to their survival, there is still a need to monitor this aspect of trade to determine any future changes. The results from this study have shown the importance of recognizing and understanding the cultural values particularly those that are innate to devising more encompassing pangolin conservation strategies and policies. Considering that the institutional capacity of state institutions to enforce wildlife regulation is very limited, there is a need to increase public awareness about the conservation and legal status of pangolins among the general public, particularly local rural communities.

\section{ACKNOWLEDGMENTS}

The author would like to thank all the stakeholders who willingly volunteered their time to provided information towards the completion of this study. The author is also grateful to Reuben Gyamfi and Osman Nuru Gaddafi for their assistance with data collection, Ziongate Geospatial and Research Services Limited for providing map of the study area and Prof. Raymond Jansen of the Tshwane University of Technology for proof reading the manuscript and providing useful suggestions. For financial support, the author would like to thank the Rufford Small Grant Foundation (Grant Number 21976-2) for providing funding for this study.

\section{REFERENCES}

Acedo-Carmona C, Gomila A (2015a) Trust matters: a cross-cultural comparison of Northern Ghana and Oaxaca groups. Frontiers in Psychology 6:661. doi: 10.3389/fpsyg.2015.00661

Acedo-Carmona C, Gomila A (2015b) Deciding to cooperate in northern Ghana: trust as an evolutionary constraint across cultural diversity. The Spanish Journal of Psychology 18:E91. doi: 10.1017/sjp.2015.102.

Adeola MO (1992) Importance of wild animals and their parts in the culture, religious festivals, and traditional medicine, of Nigeria. Environmental Conservation 19(2): 125-134.

Agada M, Igbokwe E (2016) Influence of food culture and practices on household food security in north central Nigeria. Journal of Food Security 4(2):36-41.

Akpona HA, Djagoun CAMS, Sinsin B (2008) Ecology and ethnozoology of the threecusped pangolin Manis tricuspis (Mammalia, Pholidota) in the Lama forest reserve, Benin. Mammalia 72:198-202.

Albuquerque UP, Lucena RFP, Monteiro JM, Florentino ATN, Almeida CFCBR (2006) Evaluating two quantitative ethnobotanical techniques. Ethnobotany Research and Applications 4:051-060.

Alhassan S (2015) Determinants of family low income in urban Zongo communities: the case study of selected communities in the Kumasi metropolis (Aboabo, Sawaba, Asawase and Ayigya Zongo communities in the Kumasi metropolis). MPhil dissertation, Kwame Nkrumah University of Science and Technology, Kumasi, Ghana.

Alves RRN, Neta ROS, Trovão DMBM, Barbosa JEL, Barros AT, Dias TLP (2012) Traditional uses of medicinal animals in the semi-arid region of Northeastern Brazil. Journal of Ethnobiology and Ethnomedicine 8:41 https://doi.org/10.1186/1746-4269-8-41 
Asante R, Gyimah-Boadi E (2004) Ethnic structure, inequality and governance of the public sector in Ghana. United Nations Research Institute for Social Development (UNRISD).

Awedoba AK (2006) The peoples of northern Ghana. [www.ghanaculture.gov.gh] Accessed 03 December 2017

Babbie E (2004) The practice of social research. Thomson/Wadsworth, California.

Boakye MK, Kotze A, Dalton DL, Jansen R (2016a) Unravelling the pangolin bushmeat commodity chain and the extent of trade in Ghana. Human Ecology DOI: 10.1007/s10745016-9813-1

Boakye MK (2016b) Pangolins in peril: a perspective of their use as traditional medicine and bushmeat in West Africa. DTech Thesis, Tshwane University of Technology, Pretoria, South Africa.

Boakye MK, Pietersen DW, Kotze A, Dalton D, Jansen R (2015). Knowledge and uses of African pangolins as a source of traditional medicine in Ghana. PLOS ONE 10(1): e0117199. doi:10.1371/journal.pone.0117199

Boakye MK, Pietersen DW, Kotze A, Dalton D, Jansen R (2014) Ethnomedical use of African pangolins by traditional medical practitioners in Sierra Leone. Journal of Ethnobiology and Ethnomedicine $10: 76$

https://doi.org/10.1186/1746-4269-10-76

Chithra M, Prabhu Kumar KM, Geetha SP (2016) A comparative study on ethanobotanical usage of plants for twenty selected diseases by six tribal communities in Malappuram district. International Journal of Herbal Medicine 4(4):108-113.

Codjia JE, Yorou NS (2014) Ethnicity and gender variability in the diversity, recognition and exploitation of wild useful fungi in Pobè region (Benin, West Africa). Journal of Applied Biosciences 78:6729-6742.

Conservation International-Ghana (2002) Assessment of bushmeat trade during the annual closed season on hunting in Ghana. [http://www.fao.org/docrep/010/ai793e/ai793e00. HTM] Accessed 30 October 2017

Cowlishaw G, Mendelson S, Rowcliffe JM (2005) Structure and operation of a bushmeat commodity chain in southwestern Ghana. Conservation Biology 19(1):139-149.
Fa JE, Seymour S, Dupain J, Amin R, Albrechtsen L, Macdonald D (2006) Getting to grips with the magnitude of exploitation: bushmeat in the Cross-Sanaga rivers region, Nigeria and Cameroon. Biological Conservation 129:497-510.

Fa JE, Olivero J, Real R, Farfán MÁ, Nasi R (2015) Disentangling the relative effects of bushmeat availability on human nutrition in central Africa. Scientific Reports 5:8168. doi: 10.1038/srep08168.

Gadegbeku C, Wayo R, Ackah-Badu G, Nukpe E, Okai A (2013) Food taboos among residents at Ashongman - Accra, Ghana. Food Science and Quality Management 15:21-29.

Ghana Statistical Service (2012) 2010 Population \& housing census summary report of final results.

[http://www.statsghana.gov.gh/docfiles/2010phc/ Census2010_Summary_report_of_final_results.p df] Accessed 20 June 2017

Ghana Statistical Service (2008) Ghana living standards survey. Report of the fifth round (GLSS

5).

[http://www.statsghana.gov.gh/docfiles/glss5_rep ort.pdf] Accessed 19 June 2017

Goody J, Goody E (1995) Food and identities: changing patterns of consumption in Ghana. The Cambridge Journal of Anthropology 18(3):114.

IUCN (2017) The IUCN Red List of Threatened Species. Version 2017-3. [www.iucnredlist.org] Accessed 30 December 2017

James BT (2014) Writing stones and secret shrines: an exploration of the materialisation of indigenous and Islamic belief with West African spiritual medicine. In: Gemi-lordanou E, Gordon S, Matthew R, McInnes E, Pettitt R (eds) Medicine, Healing and Performance. Oxbow Books, Oxford, pp. 136-159.

Junsongduang $\mathrm{A}$, Balslev $\mathrm{H}$, Inta A, Jampeetong A, Wangpakapattanawong $P(2014)$ Karen and Lawa medicinal plant use: uniformity or ethnic divergence? Journal of Ethnopharmacology151:517-527.

Kamins AO, Marcus-Rowcliffe J, Ntiamoa-Baidu Y, Cunningham AA, Wood JLN, Restif O (2015) Characteristics and risk perceptions of Ghanaians potentially exposed to bat-borne zoonoses through bushmeat. Eco-Health 12:104-120. 
Konadu K (2008) Medicine and anthropology in twentieth century Africa: Akan medicine and encounters with (medical). Anthropology. African Studies Quarterly 10(2\&3):45-69.

Koura K, Ganglo JC, Assogbadjo AE, Agbangla $C$ (2011) Ethnic differences in use values and use patterns of Parkia biglobosa in Northern Benin. Journal of Ethnobiology and Ethnomedicine 7:42.

Kouame OML, Jengre $N$, Kobele $M$, Knox $D$, Ahon DB, Gbondo J, Gamys J, Egnankou W, Siaffa D, Okoni-Williams A, Saliou M (2012) Key biodiversity areas identification in the Upper Guinea forest biodiversity hotspot. Journal of Threatened Taxa 4(8):2745-2752.

Kujawska M, Hilgert NI, Keller HA, Gil G (2017) Medicinal Plant Diversity and Inter-Cultural Interactions between Indigenous Guarani, Criollos and Polish Migrants in the Subtropics of Argentina. PLOS ONE 12(1): e0169373. doi:10.1371/journal.pone.0169373

Kusi-Bempah M (2011) Spatial analysis of the use of traditional medicine in urban areas of Ghana a case study of Kumasi metropolis. MPhil dissertation, Kwame Nkrumah University of Science and Technology, Kumasi, Ghana.

McCune B, Mefford MJ (2006) PC-ORD. Multivariate Analysis of Ecological Data. Version 5.10. MjM Software, Gleneden Beach, Oregon.

McNamara J, Rowcliffe M, Cowlishaw. G, Alexander JS, Ntiamoa-Baidu Y, Brenya A, Milner-Gulland EJ (2016) Characterising Wildlife Trade Market Supply Demand Dynamics. PLOS ONE 11(9):

e0162972.doi:10.1371/journal.pone.0162972

Medeiros PM, Campos JL, Albuquerque, UP (2016) Ethnicity, income, and education. In: Albuquerque UP, Alves RRN (eds) Introduction to ethnobiology. Springer, New York, pp. 245-249.

Menendez-Baceta G, Aceituno-Mata L, ReyesGarcía V, Tardío J, Salpeteur M, Pardo-deSantayana M (2015) The importance of cultural factors in the distribution of medicinal plant knowledge: a case study in four Basque regions. Journal of Ethnopharmacology 161:116127.

Mensah C, Agboka JA, Azilla-Gbettor EM (2016) Selection of traditional catering establishments in Ghana: diners' perspectives. Journal of Foodservice Business Research DOI:
Ministry of Environment and Science (2002) National biodiversity strategy for Ghana [http://www.cbd.int/doc/world/gh/gh-nbsap-01en.pdf] Accessed 16 October 2017

Morsello C, Yagüe B, Beltreschi L, van Vliet N, Adams C, Schor T, Quiceno-Mesa MP, Cruz D (2015) Cultural attitudes are stronger predictors of bushmeat consumption and preference than economic factors among urban Amazonians from Brazil and Colombia. Ecology and Society 20(4):21.

Nestle M, Wing R, Birch L, DiSogra L, Drewnowski A, Middleton S, Sigman-Grant M, Sobal J, Winston M, Economos C (1998) Behavioral and social influences on food choice. Nutrition Reviews 56: 50-64.

Nti CA (2008) Household dietary practices and family nutritional status in rural Ghana. Nutrition Research and Practice 2(1):35-40.

Ntiamoa-Baidu Y (1995) Conservation education in threatened species management in Africa. Bird Conservation International 5(4): 455-462.

Offei-Ansah C (2013) Food habits and preferences as a factor in the choice of meals by students in the University of Cape Coast. Nutrition and Health 21(3):151-172.

Onyinah O (2002) Deliverance as a way of confronting witchcraft in modern Africa: Ghana as a case history. Asian Journal of Pentecostal Studies 5(1):107-134.

Opoku K, Ankrah GK, Nyanta D (2017) Multilingualism in Techiman Zongo community. World Wide Journal of Multidisciplinary Research and Development. 3(4):11-24.

Pailler S (2005) The necessity, complexity and difficulty of resolving the bushmeat crisis in west-central Africa. Journal of Development and Social Transformation 2:99-107.

Soares DTN, Sfair JC, Reyes-García V, Baldauf C (2017) Plant knowledge and current uses of woody flora in three cultural groups of the Brazilian semiarid region: does culture matter? Economic Botany 71(4):314-329.

Soelberg J, Asase A, Akwetey G, Jager AK (2015) Historical versus contemporary medicinal plant uses in Ghana. Journal of Ethnopharmacology 160:109-132. 
Soewu DA, Ayodele IA (2009) Utilisation of pangolin (Manis sps) in traditional Yorubic medicine in ljebu province, Ogun State, Nigeria. Journal of Ethnobiology and Ethnomedicine 5: 39.

Soewu DA, Adekanola TA (2011) Traditionalmedical knowledge and perception of pangolins (Manis sps) among the Awori people, Southwestern Nigeria. Journal of Ethnobiology and Ethnomedicine 7:25.

Soewu DA, Sodeinde OA (2015) Utilization of pangolins in Africa: fuelling factors, diversity of uses and sustainability. International Journal of Biodiversity and Conservation 7(1):1-10.

Thomas E, Vandebroek I, Sanca S, Van Dammem P (2009) Cultural significance of medicinal plant families and species among Quechua farmers in Apillapampa, Bolivia. Journal of Ethnopharmacology 122: 60-67
Vandebroek I (2016) Cultural comparisons in ethnobiological research. In: Albuquerque UP, Alves RRN (eds) Introduction to ethnobiology. Springer, New York, pp. 265-271.

Vandebroek I (2010) The dual intracultural and intercultural relationship between medicinal plant knowledge and consensus. Economic Botany 64(4):303-317.

Van Vliet N, Mbazza P (2011) Recognizing the multiple reasons for bushmeat consumption in urban areas: a necessary step toward the sustainable use of wildlife for food in central Africa. Human Dimensions of Wildlife: An International Journal 16:45-54.

White $P$ (2015) The concept of diseases and health care in African traditional religion in Ghana. HTS Teologiese Studies / Theological $\begin{array}{llllll}\text { Studies } & 71 & \text { (3) } & \text { a2762 } & \text { DOI: }\end{array}$ https://doi.org/10.4102/hts.v71i3.27
Received: 18 August 2018

Accepted: 23 September 2018

Published: 19 Oct0ber 2018 